\title{
A new endemic genus of eomyid rodents from the early Miocene of Japan
}

Yuri Kimura, Yukimitsu Tomida, Daniela C. Kalthoff, Isaac Casanovas-Vilar, and Thomas Mörs Acta Palaeontologica Polonica 64 (2), 2019: 303-312 doi:https://doi.org/10.4202/app.00558.2018

Fossil rodents are generally scarce in the Miocene of Japan. However, as much as three taxa of eomyid rodents had been reported from the early Miocene Nakamura Formation (ca. 18.5 Ma) in Gifu Prefecture, central Japan. In this study, we revisit one of them-the small-sized taxon-and assign this material to a new genus, Japaneomys, which is so far known only from the type locality. The new genus is closely related to but distinguished from Asianeomys , which is more widely distributed in Central and East Asia, by having: (i) more bunodont cheek teeth with lower lophids, yet complete transverse lophids; (ii) two-rooted p4; (iii) anterior lobe narrower than posterior lobe on $\mathrm{m} 1$, correspondingly synclinid I shorter and shallower than synclinid IV; (iv) hypolophid anteriorly concave on m1. Japaneomys shows a derived but peculiar four-layered enamel microstructure with longitudinally oriented Hunter-Schreger bands, compared to three-layered microstructure in typical eomyid rodents. A phylogenetic analysis indicates that Japaneomys is more basal than Asianeomys and likely diverged in the late Oligocene when Japan was still part of the eastern margin of continental Asia, suggesting that certain small mammal populations could have undergone allopatric speciation isolated from inner-continental regions of Asia.

Key words: Mammalia, Rodentia, Eomyidae, enamel microstructure, dental morphology, time-scaled phylogeny, paleogeography, Miocene, Japan.

Yuri Kimura [ykimura.research@gmail.com] and Yukimitsu Tomida [y-tomida@kahaku.go.jp

], Department of Geology and Paleontology, National Museum of Nature and Science, 4-1-1 Amakubo, Tsukuba, Ibaraki, 305-0005, Japan. Daniela C.

Kalthoff [daniela.kalthoff@nrm.se], Department of Zoology, Swedish Museum of Natural History, P.O. Box 50007, SE-104 05 Stockholm, Sweden. Isaac Casanovas-Vilar [isaac.casanovas@icp.cat], Grup de Faunes del Neogen i Quaternari, Institut Català de Paleontologia Miquel Crusafont, ICTA-ICP; Edifici Z. Carrer de les Columnes, s/n., Campus de la Universitat Autònoma de Barcelona, E-08193 Cerdanyola del Vallès, Barcelona, Spain. Thomas Mörs [thomas.moers@nrm.se], Department of Palaeobiology, Swedish Museum of Natural History, P.O. Box 50007, SE-104 05 Stockholm, Sweden. 
This is an open-access article distributed under the terms of the Creative Commons Attribution License (for details please see creativecommons.org), which permits unrestricted use, distribution, and reproduction in any medium, provided the original author and source are credited.

Forf Full text $(433.3 \mathrm{kB})$ ।

Far 5 Supplementary file $(135.3 \mathrm{kB})$ 